\title{
Outcome of Syed's Modified Pubo-Vaginal Fascial Rectus Sling Surgery in the Treatment of Female Urinary Incontinence - A Single Centre Experience
}

Dr. Syed Sajjad Nazir ${ }^{*}$, Dr. Shahnawaz Rasool ${ }^{2}$, Dr. Javid A Magray ${ }^{3}$, Dr. Shabir A Mir ${ }^{4}$, Dr. Fuad S Baqal ${ }^{4}$, Dr. Omar S Akhter ${ }^{5}$, Dr. Tanveer I Dar ${ }^{6}$, Dr. Saleem Javid ${ }^{2}$

\footnotetext{
${ }^{1}$ Associate Professor \& Head, Department of Urology, Super Speciality Hospital, Government Medical College, Srinagar, Jammu and Kashmir, India ${ }^{2}$ Senior Resident, Department of Urology, Super Speciality Hospital, Government Medical College, Srinagar, Jammu and Kashmir, India ${ }^{3}$ Consultant, Department of Urology, Super Speciality Hospital, Government Medical College, Srinagar, Jammu and Kashmir, India ${ }^{4}$ DNB Resident, Department of Urology, Super Speciality Hospital, Government Medical College, Srinagar, Jammu and Kashmir, India ${ }^{5}$ Lecturer, Department of Urology, Super Speciality Hospital, Government Medical College, Srinagar, Jammu and Kashmir, India

${ }^{6}$ Assistant Professor, Department of Urology, Super Speciality Hospital, Government Medical College, Srinagar, Jammu and Kashmir, India
}

DOI: $10.36347 /$ sjams.2020.v08i07.013

| Received: 02.07.2020 | Accepted: 09.07.2020 | Published: 14.07.2020

*Corresponding author: Dr. Syed Sajjad Nazir

Abstract

Objective: We Modified the technique of pubo-vaginal fascial rectus sling to make it minimally invasive, less expensive and reduce the incidence of post operative urinary dysfunction. Material and Methods: This study was conducted over a period of ten years on 147 patients who were operated from Jan 2003 to Jan 2013, and followed till Jan 2020. Female patients with age range from 25-65yrs, having SUI were included in the study. Apart from the standard operative procedure of PVS, we have developed a modification in which once the prolene threads are passed above from the vaginal wound, they are not tied together as per the standard procedure but a Hemolok clip (10mm) was used bilaterally to secure the thread over the rectus sheath. Results: Operation was performed in general as well as in regional block. Mean operative time was $45 \mathrm{~min}$ with average blood loss of $100 \mathrm{ml}$. Average Sling length was $10 \mathrm{~cm}$ with a width of $2 \mathrm{cms}$. Hemolok clips $(10 \mathrm{~mm})$ were used at both ends over the rectus sheath after appropriate tension. Hospital stay was 2.4 days. Minor Complications occur in 17 pts (11.5\%). Till Jan 2020, 131pts (89.11\%) are voiding well \& have no leakage or retention, while rest of the patients $16(10.88 \%)$ are lost to follow up after 3 years. Conclusion: Syed's Modified Pubovaginal fascial rectus sling is a highly successful strategy for the management of Female urinary incontinence with a low rate of postoperative voiding dysfunction with good long term functional \& cosmetic results.

Keywords: Sling, retention, incontinence, hemolok clip.

Copyright @ 2020: This is an open-access article distributed under the terms of the Creative Commons Attribution license which permits unrestricted use, distribution, and reproduction in any medium for non-commercial use (NonCommercial, or CC-BY-NC) provided the original author and source are credited.

\section{INTRODUCTION}

Stress urinary incontinence (SUI) is a common health problem, with the prevalence rate ranging from $12.8 \%$ to $46.0 \%$. SUI has a major impact on the quality of life (QOL) of many women, and it represents a major economic burden globally [1]. The treatmentof female SUI has evolved over the last two decades. Traditional surgeries for SUI such as Burch Colposuspension and Pubo-Vaginal Sling (PVS) have slowly been supplanted by synthetic mid-urethral slings. With the recent concerns raised by the US Food \& Drug Administration (FDA) \& Health Canada about the safety of mesh implants including MUS there seems to be an important role for procedures like pubovaginal sling operation as the sling used in it is autologous origin [2].
Female SUI may be broadly subcategorized into types I, II, and III, as follows [3]:

- Type I SUI is defined as urine loss occurring in the absence of urethral hypermobility. This is the mildest form of SUI.

- Type II SUI is defined as urine loss occurring due to urethral hypermobility. This is also known as genuine stress urinary incontinence (GSUI).

- Type III SUI is defined as urine leakage occurring from an intrinsic sphincter deficiency (ISD). ISD is a more complex form of female SUI.

Indications for sling are SUI with or without cystocele, SUI with Urethral hyper-mobility, ISD with cystocele, ISD associated with urethral diverticulum, ISD in neurogenic conditions such as myelodysplasia and failed prior needle or retropubic suspension or mid- 
urethral sling operation. Athletes, obese patients, and COPD patients are benefitted significantly because of the robust nature of sling procedures.

The goal of the PVS is to provide urethral compression during times of increased intra-abdominal pressure, while not obstructing the urethra during voluntary bladder-emptying. When synthetic meshes are placed with too much tension, there is a risk of urinary retention, and rarely, erosion [4]. The concept of using increased intra-abdominal pressure to anatomically compress the urethra was proposed by Albert Aldridge in 1942, when he described using a fascial graft to relieve SUI. ${ }^{[5]}$ After several modifications were reported in the years that followed, it was McGuire and Lytton who popularized the procedure in 1978 [6]. In 1988, Blavais and Olson placed emphasis on positioning the sling at the bladder neck level in an effort to correct urethral hypermobility [7]. Delancey proposed his "hammock hypothesis" in 1994, which has further contributed to the understanding of how a sling functions to compress the urethra with increased intraabdominal pressure when placed at the bladder neck [8].

Sling material can be autologous in origin like rectus fascia, fascia lata, pyramidalis muscle, round ligament etc. Autologous slings rarely erode into bladder.

The idea behind our modification is that since the very common complication of PVS is retention of urine which results in wound being re-explored but in the presence of Hem-o-loks we can manage urinary retention by urethral dilatation only because Prolene thread gets slipped through Hem-o-Lok and tension in sling is decreased to the desired level.

\section{Material ANd Methods}

This study was conducted at the Department of Urology, Super Speciality Hospital, Government Medical College Srinagar and SKIMS Soura, Kashmir, India. Clearnce from Institutional Ethical Committee was sought. A total of 147 patients who were operated from Jan 2003- Jan 2013, operated by a single surgeon were included in this study. All patients in the study were females with history of stress urine incontinence(SUI) and which was demonstrable on physical examination and Boney test (Table-3). All baseline investigations like HMG, KFT, LFT, ECG, USG with PVR, X-ray chest, Urine examination, Cystogram, pre- and post-operatively and Cystoscopy. Patients with predominant overactive bladder (OAB) symptoms were excluded. Age of patients was 25-65 years with majority being multiparous. Informed consent was taken from all the patients in the study. The type of surgical approach was based on patient preference after explaining the patient the advantages and complications of PVS as well as other alternative procedures. Pre-operative, intraoperative and postoperative data was recorded. The procedure was defined as successful, if patients were relieved of their within 3 months after surgery with ultrasonography showing no signs of back pressure changes and PVR of $<30 \mathrm{ml}$.

\section{Statistical Methods}

The recorded data was compiled and entered in a spreadsheet (Microsoft Excel) and then exported to data editor of SPSS Version 20.0 (SPSS Inc., Chicago, Illinois, USA). Continuous variables were expressed as Mean \pm SD and categorical variables were summarized as frequencies and percentages.

\section{Surgical Techniques}

The surgery was performed under general(54) or spinal anesthesia (93), and appropriate antibiotics (second-generation cephalosporin) were administered. The patient was positioned in lithotomy with slight slight extension at hip. The following surgical technique was used:

A $6-8 \mathrm{~cm}$ transverse skin incision is made 2 $\mathrm{cm}$ above the pubic symphysis (Fig-1), and the rectus fascia is exposed. A $2 \mathrm{~cm}$ by $10 \mathrm{~cm}$ graft is marked out and incised with cautery or scalpel (Fig 2), and then mobilized off the rectus muscle. The remaining fascia is mobilized from the rectus muscle to aid in closure (Fig3 ), usually with a heavy absorbable suture. A 1-0 polypropylene (Prolene ${ }^{\circledR}$ ) suture is placed on each end of the graft (Fig-4). The graft is wrapped or soaked in $0.9 \%$ normal saline until ready for implantation. Vaginal dissection is performed after harvesting of the sling graft. Dissection is performed with the aid of a weighted speculum, with or without labial retraction. The bladder is catheterized and emptied. Hydrodissection of the anterior vaginal wall is done with $0.9 \%$ NS, with or without local anesthetic and epinephrine. A $3 \mathrm{~cm}$ vertical incision is made over anterior vaginal wall in the midurethral region (Fig-5). Lateral periurethral tunnels are created with Metzenbaum scissors and the endopelvic fascia is perforated in the superolateral direction, aiming the tips of the scissors towards the ipsilateral shoulder (Fig-6). The finger should be used to bluntly dissect a space in the retropubic region, with a goal of fitting an arm of the sling fully into the retropubic space on each side.

With the bladder completely drained, Kelly forceps are passed through the fascia on each side, approximately $1 \mathrm{~cm}$ above the pubic symphysis and approximately 2-3 cm lateral to the midline on each side (Fig-7). Both hands should be used to steady the instrument and initially penetrate through the rectus fascia immediately behind the pubic tubercle, then one hand is moved to the vaginal incision. With one hand guiding the Kelly above, the other index finger is placed through the vaginal incision into the retropubic space to meet the tip of the Kelly and guide it out through the vaginal incision. The Kelly must remain in contact with the finger-tip for the entire time it is passed so as to avoid aberrant deviation of the needle into the urethra. 
After passage of Kelly on both sides, cystoscopy is performed to ensure the bladder was not perforated. If identified, the affected Kelly is removed and passed a second time and cystoscopy repeated. The Foley catheter is replaced, and bladder drained. The ends of the graft sling suture are passed upward through the retropubic space using the Kelly clamp. The centre of the graft can be marked with marker or a clamp. The graft is positioned at the bladder neck without tension (Fig-8). The vaginal incision is closed using a running 2-0 absorbable suture. A betadine soaked vaginal gauze pack is kept.

Through the abdominal incision, the two suture arms of the sling are tied to one another across midline over the rectus fascia. At least two finger breadths should remain between the rectus fascia and the suture knot, to ensure the sling is not too tight.

\section{Our Modification}

Once the Prolene ${ }^{\circledR}$ threads are passed above from the vaginal wound, they are not tied together as per the standard procedure but a Hem-o-lok clip $(10 \mathrm{~mm})$ was used bilaterally to secure the thread over the rectus sheath after appropriate tension (Fig $9 \& 10$ ) and the two ends tied loosely (Fig-11). Rest of the procedure is same as in the standard manner. The idea behind the modification being that the very common complication of PVS is retention of urine in that case usually the wound is re-explored but because of Hem-oloks we can manage such situation by urethral dilatation only.

\section{Postoperative Care}

Patients were orally allowed on the same operative day as per the anaesthesia. Vaginal betadine gauze pack removed on first post-op day. Foley catheter was removed on day 2 For pain relief, Diclofenac infusion $(50 \mathrm{mg}$ ) was used. Patient usually discharged $2^{\text {nd }}$ post op day.

The following parameters were recorded.
- Patient's age, body mass index, any co-morbidities and surgical history.

- Approach used, blood loss, any blood transfusion.

- Operative time: defined as time of incision to skin closure

- Complications if any.

\section{RESULTS}

A total of 147 patients underwent modified PVS procedure. All patients were females in the age range of 25-65 years. A total of $69(46.9 \%)$ patients were multiparous, $41(27.8 \%)$ patients were postmenopausal, $30(20.4 \%)$ patients had history of hysterectomy, $7(4.7 \%)$ patients had history of previous failed MUS (Table-1). There was the presence of cystocele in $9(6.1 \%)$ patients. As per the etiology, 94 (63.9\%) patients had Type II SUI with grade II cystocele, $41(27.8 \%)$ patients had Type II SUI. 4 (2.7\%) patients had Type III SUI (post laminectomy),7 (4.7\%) patients had failed MUS operation(Table-2). Mean operating time was 45 minutes with average blood loss of $100 \mathrm{ml}$. Average sling length was $10 \mathrm{cms}$ with a width of $2 \mathrm{cms}$. A total of $130(88.4 \%)$ patients voided successfully on $2^{\text {nd }}$ post op day after Foley catheter removal. Seventeen patients failed the trial, and went into retention and were discharged on catheter. After 2 weeks of catherisation, 11patients out of 17 voided successfully while the 2 patients improved with urethral dilatation. 3 patients did CIC for 2 months whereas 1 patient was on CIC for 10 months. Two patients had abdominal wound infection which was managed by daily dressing. One patient developed urge incontinence which was treated with antimuscarinics (Tolteridine $4 \mathrm{mg}$ once daily for 3 months) No instance of bladder injury or bleeding from retropubic space was seen. No patient reported persistence of stress incontinence. At 3 years follow up, all patients were voiding well and at 7 years $131(89.1 \%)$ patients were doing well and $16(10.8 \%)$ patients were lost to follow up till Jan 2020 (Table-4).

Table-1: Demography

\begin{tabular}{|l|l|l|}
\hline Parameter & Description & $\mathbf{N}(\%)$ \\
\hline Age & $25-65$ & $147(100)$ \\
\hline Sex & Females & $147(100)$ \\
\hline Parity & Multipara & $69(46.9)$ \\
\hline Previous surgery & Hysterectomy & $30(20.4)$ \\
\hline & Failed MUS surgery. & $7(4.7)$ \\
\hline
\end{tabular}

Table-2: Frequency of different types of SUI

\begin{tabular}{|l|l|l|}
\hline Type & Description & $\mathbf{N}(\%)$ \\
\hline I & Urine loss occurring in the absence of urethral hypermobility & $94(63.9)$ \\
\hline II & Urine loss occurring due to urethral hypermobility & $41(27.8)$ \\
\hline III & Urine leakage occurring from an intrinsic sphincter deficiency & $4(2.7)$ \\
\hline & Previously failed MUS surgery & $7(4.7)$ \\
\hline
\end{tabular}


Table-3: Preoperative evaluation

\begin{tabular}{|l|l|l|}
\hline Variable & & $\mathrm{n}=147(\%)$ \\
\hline Cystocele & Present & $9(6.1)$ \\
\hline Pad test & Positive & $147(100)$ \\
\hline Cough test (Lying down) & Positive & $80(54.4)$ \\
\hline Cough test (Sitting) & Positive & $147(100)$ \\
\hline VLPP (cmH2O) & $60-90$ & $115(78.23)$ \\
\hline & $<60$ & $32(21.8)$ \\
\hline
\end{tabular}

Table-4: Our outcome

\begin{tabular}{|l|l|}
\hline Total no. Of patients & 147 \\
\hline Voided successfully on Day 2 & $130(88.4 \%)$ \\
\hline Voided on day 15 & $11(7.4 \%)$ \\
\hline Voided after urethral dilatation & $2(1.3 \%)$ \\
\hline Needed CIC For 2 Months & $3(2 \%)$ \\
\hline Needed prolonged CIC & $1(0.6 \%)$ \\
\hline Success at 7 years & $131(89.1 \%)$ \\
\hline
\end{tabular}

\section{Abdominal Approach:}

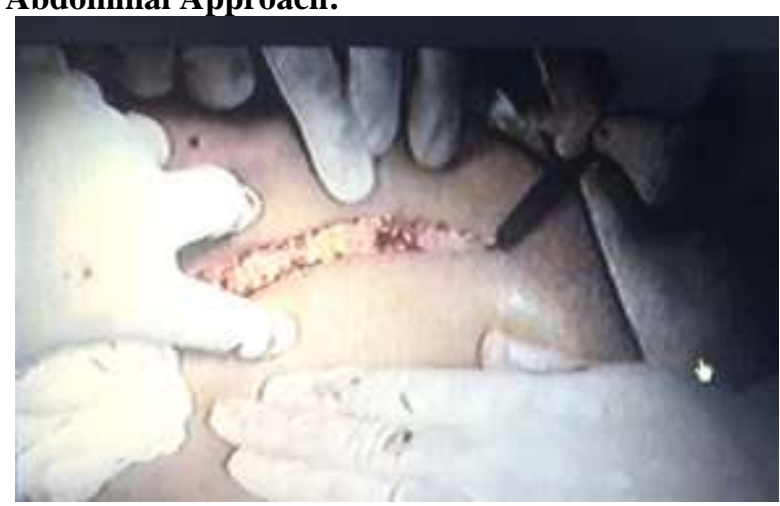

Fig-1: Abdominal incision just $2 \mathrm{cms}$ above pubic symphsis

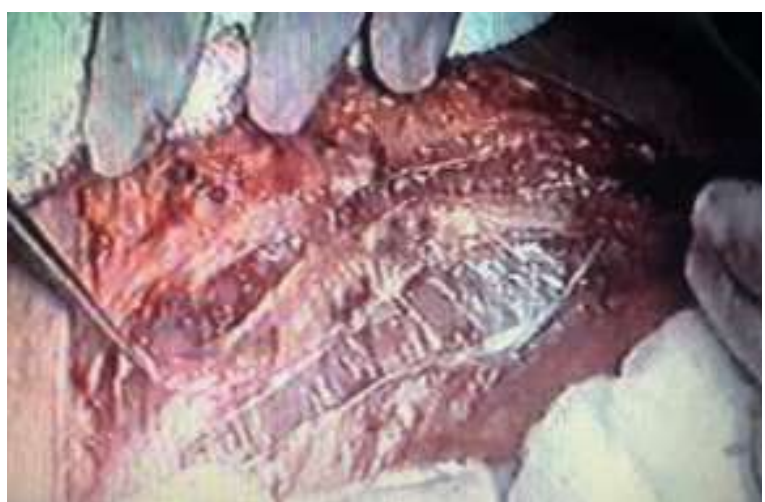

Fig-2: Rectus sheath sling marked out ( 10 cms* 2 cms)

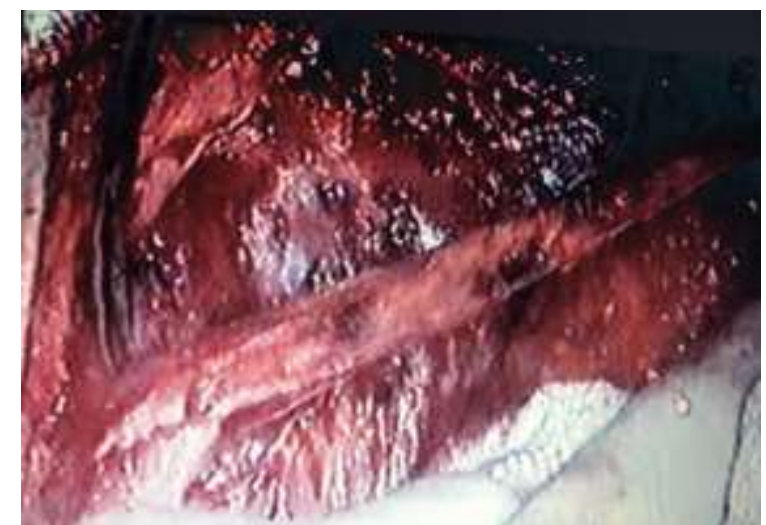

Fig-3: Rectus sheath isolated

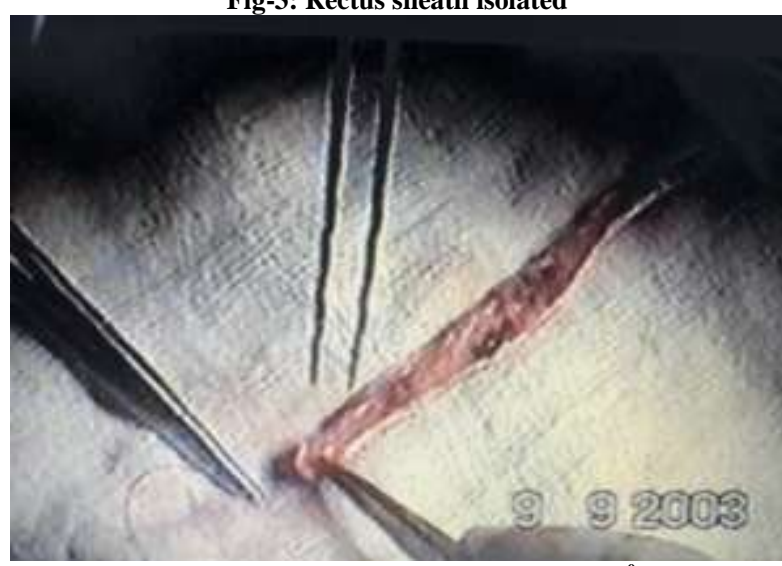

Fig-4: Two ends sutured with Prolene $\mathbf{1}^{0}$

\section{Vaginal Approach}

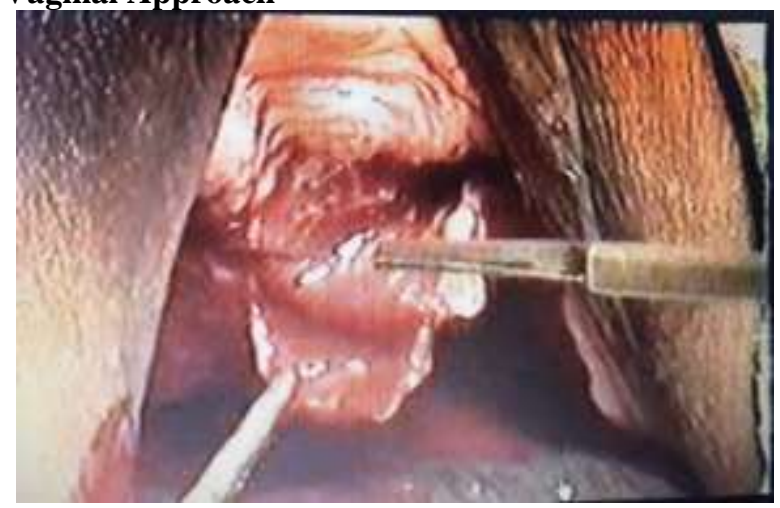

Fig-5: Midline/ inverted C incision at mid urethral area

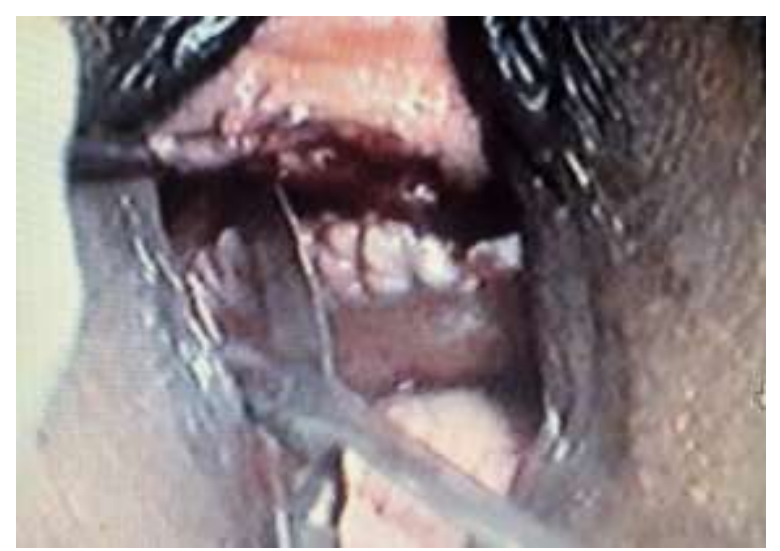


Fig-6: Lateral dissection to enter retropubic space incising endopelvic fascia

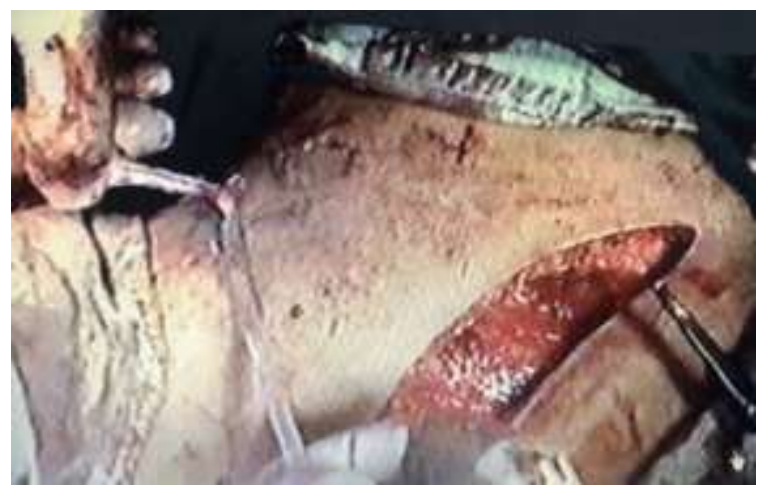

Fig-7: Rectus fascial sling passed one either sides from below to

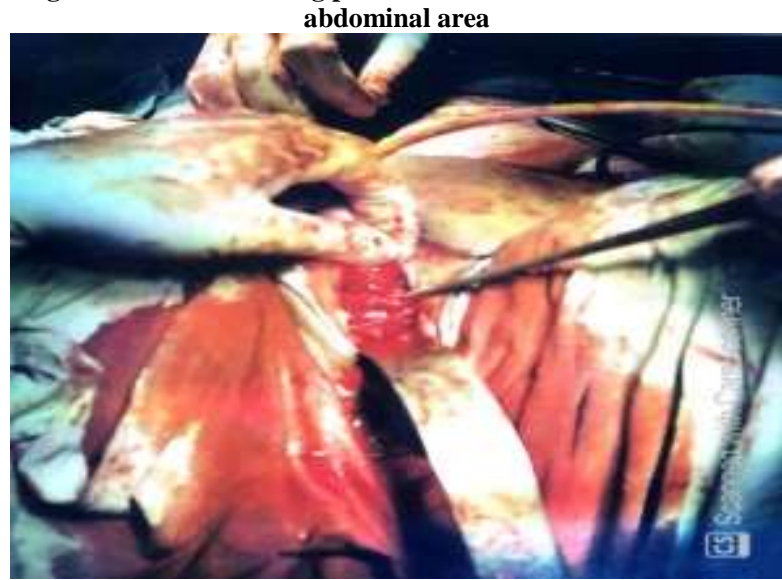

Fig-8: Vaginal aspect of Rectus Sling been placed at mid urethra

\section{Our Modification:}

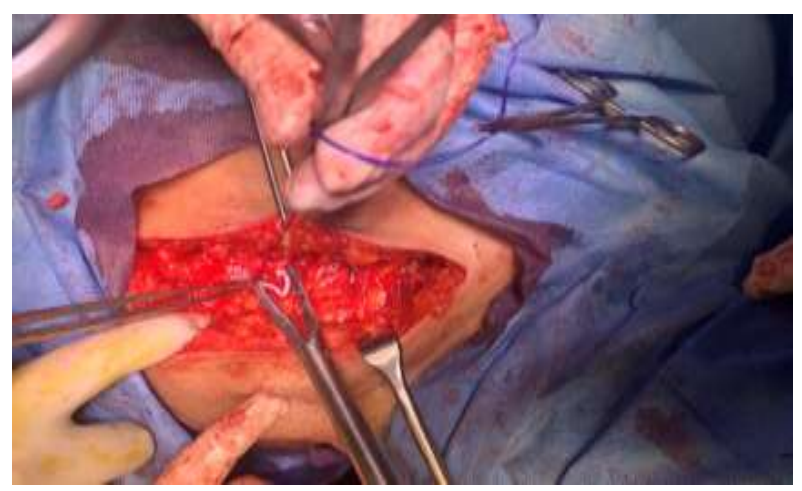

Fig-9: Applying Hemolok clips (10mm) to prolene at each end over rectus sheath

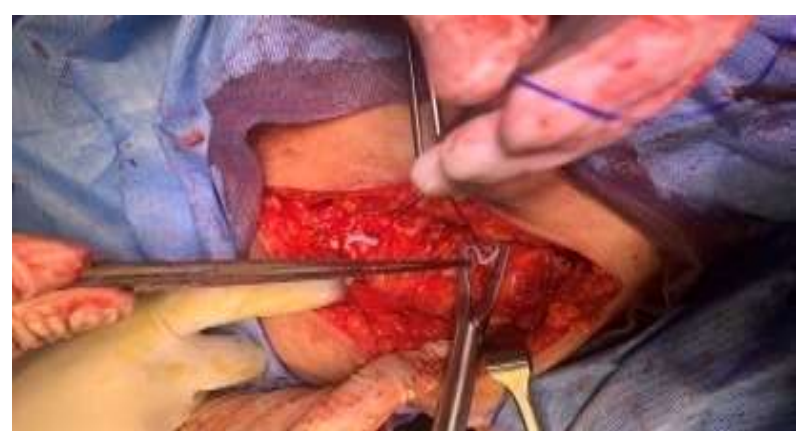

Fig-10: Both ends of the prolene fixed with Hemolok clips over the rectus sheath

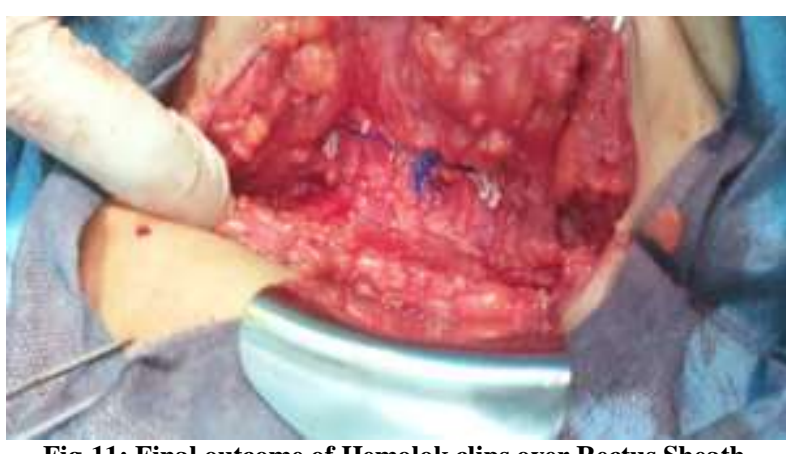

Fig-11: Final outcome of Hemolok clips over Rectus Sheath, prolene ends tighted loosely before wound closure

\section{Discussion}

Stress urinary incontinence (SUI) is defined as the involuntary leakage of urine with effort or exertion, such as physical exercise, sneezing or coughing. Approximately $50 \%$ of all women experience SUI symptoms [9]. Because of social stigma, an estimated $50-70 \%$ of women with urinary incontinence do not seek medical evaluation and treatment. Of individuals with urinary incontinence, only $5 \%$ in the general community and $2 \%$ in nursing homes receive appropriate medical evaluation and treatment. Patients with urinary incontinence often endure this condition for 6-9 years before seeking medical therapy [3]. There are many different surgical interventions that can be considered for women with stress urinary incontinence (SUI). It thus falls to the clinician to help select the most appropriate intervention for each individual patient [10]. Taken in aggregate, the apparent weight of the available evidence suggests that sling procedures are probably more efficacious than retropubic bladder neck suspensions. When comparing sling procedures, the efficacy of the autologous PVS and the midurethral sling (MUS) appears similar [10].

Synthetic suburethral slings have become the most widely used technique for the surgical treatment of stress urinary incontinence. Despite its high success rates, significant complications have been reported including bleeding, urethral or bladder injury, urethral or bladder mesh erosion, intestinal perforation, vaginal extrusion of mesh, urinary tract infection, pain, urinary urgency and bladder outlet obstruction.

Recent warnings from important regulatory agencies worldwide concerning safety issues of the use of mesh for urogynecological reconstruction have had a strong impact on patients as well as surgeons and manufacturers [9]. The FDA recommendations for surgeons treating SUI is to inform the patient about her choice to have incontinence repair with or without a mesh sling [11].

The FDA recommendations seem clearly pointing towards the serious risks associated with synthetic slings and in view of similar success rates 
from autologous slings, want the patients to know about it and select autologous slings as the preferred treatment.

The success rate of about $100 \%$ at 3 years and $89.11 \%$ at 7 years for pubovaginal rectus sheath sling in our present study, is comparable to the Cross et al., and Sherif et al., studies [12, 13]. A critical element is tying the suspension sutures to ensure continence without obstruction.

If the sling is over-suspended or if excessive scarring occurs, delayed voiding or urethral obstruction may develop. Temporary urinary retention, necessitating self-intermittent catheterization, is rare (approximately 5\%) but may occur following surgery.

Studies show an incidence rate of $3 \%$ for urethral obstruction by the sling. Chronic urinary retention from urethral obstruction may be corrected by urethrolysis or treated with lifelong intermittent catheterization. After MUS procedures, surgical release for refractory postoperative VD procedures has been indicated for $1-2 \%$ of women [14].

For this we have developed a modification, which offers room for non-surgical re-adjustment in case of retention after surgery. Once the Prolene ${ }^{\circledR}$ threads are passed above from the vaginal wound, they are not tied together as per the standard procedure but a Hem-o-lok clip (10 mm) is used bilaterally to secure the thread over the rectus sheath after appropriate tension.In case retention of urine occurs post-op; with Hem-o-loks we can manage such situation by urethral dilatation only. This makes the procedure an attractive option.

New-onset urge incontinence occurs in 15$20 \%$ of individuals and to ensure that the patient is emptying, post-void residual should be checked. Infection should also be ruled out. Should the problem(s) persist, the initial management should be behavioural, followed by anticholinergic therapy [15].

\section{Conclusions}

We conclude that Syed's Modified PuboVaginal Fascial Rectus Sling is an effective \& appropriate solution with minimal morbidity \& mortality, especially after failed MUS mesh, ISD \&cystocele; with good long term functional \& cosmetic results. Moreover, Syed's Modification in the procedure makes it patient satisfying and surgeon friendly. We hope that with this simple modification more surgeons will get interested in this procedure Further studies are needed to assess the success rates of this modification at other centres.

Acknowledgments: Mr. Mohammad Yaseen Wani (OT Supervisor) for his help and maintaining operation records.

\section{Conflict of Interest: None Funding: Nil}

\section{REFERENCES}

1. Luo DY, Wang KJ, Zhang HC, Dai Y, Yang TX, Shen H. Different sling procedures for stress urinary incontinence: a lesson from 453 patients. The Kaohsiung journal of medical sciences. 2014 Mar 1;30(3):139-45.

2. Information Regarding the Transvaginal Implantation of Surgical Mesh Devices for the Treatment of Pelvic Organ Prolapse and Stress Urinary Incontinence [Internet]. [cited 2020 May 25]. Available from: https://www.healthycanadians.gc.ca/recall-alertrappel-avis/hc-sc/2014/39507a-eng.php

3. Vaginal Sling Procedures: Overview, Preparation, Technique. 2019 Dec 5 [cited 2020 May 29]; Available from: https://emedicine.medscape.com/article/447951overview

4. Bailly GG, Carlson KV. The pubovaginal sling: Reintroducing an old friend. Can Urol Assoc J J Assoc Urol Can. 2017 Jun; 11(6Suppl2):S147-51.

5. Aldridge $\mathrm{AH}$. Transplantation of fascia for relief of urinary stress incontinence. Am J Obstet Gynecol. 1942 Sep 1;44(3):398-411.

6. Mcguire EJ, Lytton B. Pubovaginal sling procedure for stress incontinence. J Urol. 1978 Jan; 119(1):82-4.

7. Blaivas JG, Olsson CA. Stress incontinence: classification and surgical approach. J Urol. 1988 Apr;139(4):727-31.

8. DeLancey JO. Structural support of the urethra as it relates to stress urinary incontinence: the hammock hypothesis. Am J Obstet Gynecol. 1994 Jun; 170(6):1713-20; discussion 1720-1723.

9. Gomes CM, Carvalho FL, Bellucci $\mathrm{CH}$, Hemerly TS, Baracat F, Bessa Jr JD, Srougi M, Bruschini H. Update on complications of synthetic suburethral slings. International braz j urol. 2017 Oct;43(5):822-34.

10. Surgical management of stress urinary incontinence: A rational approach to treatment selection [Internet]. [cited 2020 May 22]. Available from: https://www.ncbi.nlm.nih.gov/pmc/articles/PMC3 481938/

11. Health C for D and R. Recommendations for Health Care Providers Treating Stress Urinary Incontinence. FDA [Internet]. 2019 Apr 16 [cited 2020 May 29]; Available from: https://www.fda.gov/medicaldevices/urogynecologic-surgical-meshimplants/recommendations-health-care-providerstreating-stress-urinary-incontinence

12. Mourad S, Elshawaf H, Ahmed M, Mostafa DE, Gamal M, Shorbagy AA. Autologous versus synthetic slings in female stress urinary incontinence: A retrospective study. Arab J Urol. 2018 Jul 9;16(4):397-403. 
13. Cross CA, Cespedes RD, McGuire EJ. Our experience with pubovaginal slings in patients with stress urinary incontinence. J Urol. 1998 Apr;159(4):1195-8.

14. Çelik H, Harmanlı Ö. Evaluation and management of voiding dysfunction after midurethral sling procedures. J Turk Ger Gynecol Assoc. 2012 Jun $1 ; 13(2): 123-7$.

15. Nitti VW. Complications of midurethral slings and their management. Can Urol Assoc J. 2012 Oct;6(5 Suppl 2):S120-2. 